\title{
Role of Smart Phone Apps on Smart Phone Addiction Among Nigerian Undergraduates: Impact of Age, Gender, and Phone-Type
}

\author{
Esther Ukwuoma Orji ${ }^{1,4,}$, Levi-Lortyom Doofan Jennifer ${ }^{1,4}$, Malla Naomi ${ }^{1,4}$, \\ Ewah-Otu Beatrice $^{1,4}$, Ugwu Gloria Ifeoma ${ }^{2,4}$, Asogwa Kelechukwu Deborah ${ }^{3,4}$ \\ ${ }^{1}$ Department of Social Sciences, School of General and Basic Studies, Unwana, Nigeria \\ ${ }^{2}$ Department of Information and Communication Technology, Directory Division, Unwana, Nigeria \\ ${ }^{3}$ Department of Entrepreneurship Education, Directory Division, Unwana, Nigeria \\ ${ }^{4}$ Akanu Ibiam Federal Polytechnic, Unwana, Nigeria
}

\section{Email address:}

esther173512@yahoo.com(Esther U. O.), fabdoofan2@gmail.com (Levi-Lortyom D. J), mallasally65@gmail.com (Malla N.), E.beatrice2e@uahoo.com (Ewah-Otu B.), gloriagoziem@gmail.com (Ugwu G. I.), kelechukwudebby@gmail.com (Asogwa K. D.)

${ }^{*}$ Corresponding author

\section{To cite this article:}

Esther Ukwuoma Orji, Levi-Lortyom Doofan Jennifer, Malla Naomi, Ewah-Otu Beatrice, Ugwu Gloria Ifeoma, Asogwa Kelechukwu Deborah. Role of Smart Phone Apps on Smart Phone Addiction Among Nigerian Undergraduates: Impact of Age, Gender, and Phone-Type. Social Sciences. Vol. 9, No. 5, 2020, pp. 155-159. doi: 10.11648/j.ss.20200905.13

Received: June 23, 2020; Accepted: July 17, 2020; Published: September 14, 2020

\begin{abstract}
The constant inclination on the use of smart phone applications (Apps) among students has gone above from normal purposes of using a smart phone to more active stage of conscious engagement in elaborate use. This has lead to one of behavioural problem prevailing among them today. This study sought to unveil the degree to which undergraduates are craving to smart phone apps and their demographic profile. Researching on the impact of Age, gender, and phone-type on Smart Phone Apps craving could probe into the prevailing variable that contributes greatly to Smart phone addiction. One hundred and two (102) undergraduates (51 males, and 51 females) aged 20 and 40 years $(M=25.35$ years, $S D=2.58)$ participated in this study. The questionnaire used include group of questions related to demographic characteristics, and the Smartphone Addiction Scale (SAS-SV) for measuring the studied variables. Purposive sampling techniques were used for data collection and Anova Statistics was used for data analysis. The result of the analysis showed that Age, and Phone-type had a significant main effect on Smart phone addiction, indicating that the age of these students and the type of phone they use aid to increase Smart phone addiction found among them. Gender did not account for Smart phone addiction. It was concluded that Age and Phone-type should be considered to be important factors in psychosocial interventions to minimize Smart phone addiction of undergraduates.
\end{abstract}

Keywords: Age, Gender, Phone Type, Smart Phone Addiction

\section{Introduction}

Behavioural problem emanating from smart phone usage is obviously alarming among undergraduate students today. Smart phone have gradually shifted student's interest on text books towards smart phone applications. Not only that it has done this, it has also generated more craving behavioural disorders which were rarely found among students in contemporary education system. It is not surprise to say that there is a gradual shifting from normal academic activities towards continuous attachment to smart phone applications. Considering the constant calling, texting, watching video, listening to music, playing games, snapping picture and chatting with friends with the aid of smart phone applications (apps), it may be assumed that moving out of the home without mobile phone may lead one to manifest one of the following behavioural disorders; disappointed mood, depression, and impulse control deficits $[8,1]$. Just as the study of [5] identified various psychological factors 
associated with the use of smart phone apps, which include; insomnia, anxiety, social stress, depression, and compulsiveness. These behavioural disorder is often and gradually internalized and occur unaware, thus, it seem to be neglected despite its effect on campus health.

Still upholding the advantages of smart phone, most people have otherwise developed an obsessive craving on its use which otherwise recently termed addiction. Phone App craving behaviour is one of smart phone addiction involving an active conscious engagement in the use of smart phone apps. This active conscious engagement often includes serious cognitive and behavioural attachment. For the fact that it involves both cognitive and behavioural attachment, it is termed addiction. Addiction itself refers to an activity that one cannot stop doing once the person started it [3]. Smart phone addiction was conceptualized as an act of engaging often on smart phone apps which do occur unnoticed, and thereby neglecting other activities. This is to say that, the active conscious engagement on smart phone apps has no time limit when started, and may lead to one of the events that consumes academic work hours among students. Invariably, [9] opined that smart phone has a mobile and internet capabilities, and therefore has the possibility of becoming a prevalent social problem considering its characteristics of addiction such as tolerance, withdrawal, difficulty of performing daily activities, or impulse control disorders. Also, [10] added that smart phone as a recent attribute of social problem is characterized by the following behavioural components; compulsive phone use, behaviours such as repeated checking for messages or updates; tolerance, longer and more intense bouts of use; withdrawal, feelings of agitation or distress without the phone, and functional impairment, interference with other life activities and face to face social relationships.

Observation has shown that, due to constant inclination on the use of phone apps, many students have begin to develop behavioural addiction towards it as they actively concentrate more on various application. Such addicted behaviour has gone too far, to the extent that phone usage has extended to various places like inside the church, in the classroom, during lectures, break time, at home, on the road, inside the car, at bed time, break-fast, lunch and dinner hours. Question concerning the remaining hour left to engage on academic related activities may not be answered by any of these students.

\subsection{Smart Phone Apps}

Smart phones as including Android, iPhone, and Windows are invariably not the same as mobile phone for the fact that, smart phones is a real-time information providers with powerful portable computer features [5]. The advantage attached to smart phone apps is assumed to suit the young generation needs and wants. Information Communication and Technology (ICT) made it easy for a smart phone to be used as a medium of interactions among new generation whereby people can create, share, and exchange information and ideas from any parts of the world through networks $[2,12]$ opined that Smart phone built-in features has generated a group of
Internet-based applications that build on the foundations of Web 2.0, and this moves the creation and exchange of usergenerated contents. Now, smart phone can be used to store different contents on the micro SD cards or the phones' internal memory [13]. Today, students are the larger number of smart phone users and it helped them to actively involved in such addicted area as in; instant messaging, e-mail, browsing, uploading and downloading games, whatsapp and facebook messaging, as well as other sites for sharing photos, videos and ideas. This behaviour has exposed many students to different kinds of contents such as; access to different types of social media and pornographic sites where they access, download, exchange and watch pornographic films of different sexual cultural orientations from all over the world [7].

\subsection{Smart Phone Addiction, Age, Gender, and Phone-Type}

The assumption that age, and gender differences, including the type of phone that a student uses may exert much influence on smart phone apps craving behaviour is the motive behind this study. This is because, the manner through which many group of students consciously engaged actively on smart phone apps is resulting to craving of phone apps of which have received scanty attention. For instance, the view that male students engage more on smart phone apps than the females may have implications in their academic functioning and campus health. The same implications may be found among their counterparts females. Again, the view that the age of the students may have implications on smart phone craving behaviour is another issue crying for help in understanding areas of intervention. Moreover, considering the type of phone a student uses could help to unveil the unit of population that have access to Smart phone, and the degree to which they are addicted to smart phone social apps. Thus, this made the researchers of this study to ask the following questions:

1) Will age predicts Smart phone addiction?

2) Will gender difference predicts Smart phone addiction?

3) Will phone type predicts Smart phone addiction?

\subsection{Literature on Age, Gender, Phone-Type and Smart Phone Addiction}

Gender differences is a variable suspected to influence the use of smart phone to its addicted level. Considering the degree to which male students and female students are constantly craving on phone apps will be an important issue that may probe into the group that needed psychological intervention, hence, it has received scanty current literature. Most literature looked into that while collaborating one or two personal factors. Lount, et.al. conducted a study on how age and gender affect smart phone usage, they discovered that females use smart phones for longer periods than that of males with a daily mean of 166.78 minutes against 154.26 minutes for male [11]. The same study revealed that younger participants use smart phones for longer periods and usage is directed towards entertainment and social interactions through specialized apps. Moyazeem examined the influence of the mobile phone usage on academic performance 
among male and female students of Jahangirnagar University, Bangladesh. Using a face to face survey on 274 students which included 159 male students and 115 female students ranging from second year to fourth year from different departments of Jahangirnagar University, Bangladesh. Their results depicts that gender, age and relationship with opposite sex have the significant positive effect on students' academic performance [14]. Haruna, et. al. investigated the influence of mobile phone usage on academic performance among secondary school students in Jalingo, Taraba State, Nigeria. Using 300 respondents, t-test and ANOVA to answer the research questions and hypotheses. The study revealed that mobile phone usage significantly influence academic performance among male and female senior secondary school students $(\mathrm{t}=6.113$, $\mathrm{P}=0.02$ ), age difference was not a significant factor in mobile phone usage on academic performance among senior secondary school students $(\mathrm{f}=6.431, \mathrm{P}=0.022)[7]$.

There is scanty of recent literature on the influencing strength of age, gender, and phone-type on Smart phone addiction. Researching on that will unveil the degree at which gender differences, age, and the type of phone a student uses greatly exert influence on this problematic behaviour. Moreover, it will serve as a source of information to the research community on this area. Hence, this study tested the following hypotheses:

1) There will be a statistically significant difference on smart phone addiction between participants with smart phone and participants with other type of phone.

2) There will be a statistically significant difference on smart phone addiction between male and female undergraduates.

3) There will be a statistically significant difference on smart phone addiction between different age group of undergraduates.

\subsection{The Present Study/Methodology}

The study sought to unveil the degree to which undergraduate students consciously engaged on smart phone apps with consideration on age, gender, and phone-type using Nigerian population. Researching on the role of smart phone apps on Smart phone addiction among Nigerian undergraduates considering the impact of Age, Gender, and Phone-type. may be helpful in detecting the prevailing variable that contributes greatly to Smart phone addiction. One hundred and two (102) undergraduates (51 males, and 51 females) aged 20 and 40 years $(M=25.35$ years, $S D=2.58)$ participated in this study. Purposive sampling techniques was used for effective collection of data.

Instrument: The questionnaire used include group of questions related to demographic characteristics, and the Smartphone Addiction Scale (SAS-SV) for measuring the studied variables. Questions on phone-type were gathered and classified based on the alternative offered to the respondents. Thus:

Smart Phone-refers to any group of phone associated with iPhone, Window, and Android.

Others-refers to any group of phone that were not among the above mentioned groups of phone.

Dv (Dependent Variable)-The researchers considered Smart Phone addiction as the subject under study using smart phone apps as the influencing factor.

Ivs (Independent Variables)-The study considered Age, Gender and Phone-type as the predictor variables.

\section{Data Analysis}

In data analysis, descriptive statistics and Anova statistics were used to determine the statistical strength and level of significant of IVs on the DV.

\section{Result}

Table 1. Summary of Mean score and standard deviation of Age, gender and Phone-type on Smart phone addiction.

\begin{tabular}{lllll}
\hline Variable & & Mean & SD & N \\
\hline Gender: & Male & 37.55 & 8.635 & 51 \\
& Female & 36.49 & 10.81 & 51 \\
Phone Type: & Smart phone & 35.93 & 9.55 & 54 \\
& Others & 38.25 & 9.92 & 48 \\
Age: & $20-24$ & 33.19 & 11.03 & 43 \\
& $25-29$ & 41.51 & 5.71 & 51 \\
& 30 and above & 29.000 & 9.75 & 8 \\
\hline
\end{tabular}

The table shows that the mean score of male participant (37.55) is slightly higher than that of female participants (36.49) on Smart phone addiction. Also, participants with smart phone had a lower mean score (35.93) than that of others (38.25) on smart phone addiction. Again, participants with the age of 24-29 had a higher mean score (41.51) on smart phone addiction than that of those of 20-24, and 30 and above. A two-way ANOVA was performed to determine if the observed differences among the groups were significant (see Table 2 below).

Table 2. ANOVA summary Table showing the effects of Age x Gender x phone-type on Smart phone addiction.

\begin{tabular}{llllll}
\hline Source of variance & Sum of square & df & Mean square & Sig \\
\hline Gender (A) & 28.588 & 1 & 28.588 & ns \\
Phone-type (B) & 137.257 & 1 & 137.257 & .299 \\
Age (C) & 2174.704 & 2 & 1087.352 & 1.451 \\
A x B x C & 412.414 & 3 & 137.471 & 14.501 & \\
Error & 9185.547 & 98 & 93.730 & \\
Total & 9597.961 & 101 & & \\
\hline
\end{tabular}

Key: $* *=$ Significant, $\mathrm{p}<.001$

$\mathrm{ns}=$ not significant 
The results indicate that Phone-type had a significant main effect on smart phone addiction, F, $(1,101)=1.45, \mathrm{p}<.001$. Hypothesis 1 was thereby accepted. On the contrary, gender had no significant main effect on smart phone addiction, F (1, $101)=.299$, ns. Hence, hypothesis 2 was rejected. Again, Age had a significant main effect on smart phone addiction, F, $(2,101)=14.50, \mathrm{p}<.001$. Hypothesis 3 was thereby accepted. The interaction effects for gender (A), Phone-type (B) and Age (C) was significant, F, $(3,101)=1.467$.

\section{Discussion}

The findings of this study clearly indicated that smart phone addiction is majorly influenced by the Age of students and the type of phone which the student uses. Just as the results from table 2 showed, participant with smart phone showed a statistically significant difference in their level of addiction to smart phone apps with those who are with other type of phones, $\mathrm{F}(1,101)=1.45, \mathrm{p}<.001$. This indicated that the first hypothesis which stated that, there will be a statistically significant difference on smart phone addiction between participants with smart phone and participants with other type of phone is accepted. The result obtained showed that phone-type influences smart phone addiction. This finding has given a new information to the role of smart phone apps on Smart phone addiction.

Moreover, the finding also revealed that students at the age between 25 to 29 had a higher mean score on smart phone addiction. The Anova statistics showed a statistically significant difference in their level of addiction with those group within 20 to 24 , and 30 and above, F, $(2,101)=14.50$, $\mathrm{p}<.001$. This indicated that the third hypothesis which stated that, there will be a statistical significant difference between different age group of students was accepted. This result is in congruence with the finding of Lount, et. al., who discovered that younger participants use smartphone for longer periods and usage is channeled towards entertainment and social interaction [11]. Moreover, the findings of this study deviated from that of Haruna, et. al. who found that age difference was not a significant factor in mobile phone usage [7].

Surprisingly, hypothesis 2 which stated that, there will be a statistically significant difference on smart phone addiction between male and female undergraduates was rejected. The Anova statistics revealed that gender had no significant main effect on smart phone addiction, $\mathrm{F}(1,101)=.299$, ns. This indicated that gender does not influence smart phone addiction. This might be that the addicted level and non addicted level between male and female undergraduates are similar. Thus, some literature revealed in this work found out that gender affect smart phone usage. Just as the study of Lount, et. al. revealed that females use smart phones for longer periods than that of males with a daily mean of 166.78 minutes vs 154.26 minutes of their counterpart males [11]. They also found that mobile phone usage significantly influence academic performance among male and female senior secondary school students. This present finding was not in congruence with them.

\section{Implication}

Smart phone addiction as an unstoppable and uncontrollable desire to use Smart phone applications without considering its negative and detrimental consequences has become the alarming social problem among undergraduates today [6]. It is an impulsive loss on smart phone apps resulting from the search for gratification and reinforcement. According to many other researchers, it is mostly found to exerts remarkable impact on academic performance of these students $[8,4,1]$ ). Observation has shown also that its usage has gone very far to the extent that it has extended to various places like inside the church, during the sermon, video capturing the preacher of the gospel and the styles of prayers, during lectures, break time, at home, on the road, inside the car, at bed time, break-fast, lunch and dinner hours. The results obtained have clearly indicated the smart phone addictive group and the causes as it revealed that population that uses smart phone are in greater percentage than those that uses other type in this study, and they can be found mostly within the age of 25 to 29 years. The findings also revealed that the pattern of usage and addiction to smart phone apps are the same between male and female students as there were no statistical significant difference between them.

Conversely, the advantage that Smart phone offers to students is assumed to suit their needs and wants. Observation has shown that students of this era uses smart phone to access internet documents, download and forward online class assignments, share social interaction and class discussion. Not only that smart phone has done the above mentioned, it has also assumed to replace the constant visitation of university or institution library. Thus, in order to belong to those that have access to the above online mode, many students have gradually shifted the academic advantage of smart phone to social life advantage.

It is anticipated by the researchers that, though the use of awareness probes in the context of the influence of age and phone-type on smart phone addiction among undergraduate students, a larger sample size is hope to shed further light on this phenomenon.

The limitation of this study lies on the small sample size used, though the sample size is small, the study did enable us to gain an insight into the detrimental effect of age, and phone-type on smart phone apps craving.

\section{Conclusion}

The problem investigated was the influencing strength of Age, Gender, and Phone Type on smart phone addiction. Age of the student and the type of phone they use exerts much influence on smart phone craving behaviour. It was also found that smart phone addiction is a social alarming problem today which is dangerous when associated it to academic performance, use of library, reading, and learning of course related materials. The Nigeria society, including 
administration and staff believe that younger people with smart phone feel addicted to social apps thereby neglecting other school related work.

This study looked into this issue by using group of questions related to the studied variables and Anova statistics to gather relevant data and to reveal the statistical strength of the studied variables. The result showed that Age and Phonetype has implication on smart phone addiction. The study also showed that Gender did not differ significantly in smart phone craving among undergraduates suggesting that gender did not moderate the relationship between its differences and smart phone addiction.

\section{References}

[1] Bianchi, A., \& Phillips, J. Psychological predictors of problem mobile phone use. Cyber Psychology and Behavior, 8 (1) (2005): 39-51.

[2] Blumenstock, J. J., \& Eagle, N. Mobile Divides: Gender, Socioeconomic Status, and Mobile Phone Use in Rwanda. U. C. Berkeley School of Information Berkeley, (2010). CA 94720 .

[3] Cambridge Advanced Lerner's Dictionary, (2008). Third edition.

[4] Chaudhury, P., \& Tripathy, H. K. A study on impact of smartphone addiction on academic performance. International Journal of Engineering and Technology 7 (2.6) (2018). 50-53.

[5] Chen, B., Lui, F, Ding, S., Ying, X., Wang, L., \& Wen, Y. Gender differences in factors associated with Smart Phone addiction: A cross-sectional study among medical college students. BMC Psychiatry, (2017). 17: 341 DOI 10.1186/s12888-017-1503-z.

[6] De-Sola J, Talledo H, Rubio G and de Fonseca FR.
Development of a Mobile Phone Addiction Craving Scale and Its Validation in a Spanish Adult Population. Front. (2017) Psychiatry 8: 90. doi: 10.3389/fpsyt.2017.00090.

[7] Haruna, R., Aisha, I. M., Yunusa, U., \& Hadiza, T. A. Impact of mobile phone usage on Academic Performance Among Secondary School Students In Taraba State, Nigeria. European Scientific Journal 12, (1) (2016). ISSN: 1857-7881 (Print) eISSN 1857-7431.

[8] Khan, A. A., Khalid, A., \& Iqbal, R. Revealing the Relationship between Smartphone Addiction and Academic Performance of Students: Evidences from Higher Educational Institutes of Pakistan. Pakistan Administrative Review, 3 (2), (2019). 74-83. https://nbn-resolving.org/urn:nbn:de: 0168ssoar-63203-4.

[9] Kwon, M., Kim D-J., Cho, H., \& Yang, S. The Smartphone Addiction Scale: Development and Validation of a Short Version for Adolescents. (2013). PLoS ONE 8 (12): e83558. doi: 10.1371/journal.pone.0083558.

[10] Lin, Y. H., Chiang, C. L., Lin, P. H., Chang, L. R., Ko, C. H., Lee, Y. H., Lin, S. H. Proposed diagnostic criteria for Smartphone addiction. (2016). PLoS One; 11 (11): e163010.

[11] Lount. Alexander, \& Christian. The prevalence of smart phone addiction among participants was $29.8 \%$ (30.3\% in males and $29.3 \%$ in females). (2016). ACM 978-1-4503-4462-3/16/09. http://dx.doi.org/10.1145/2968219.2971451.

[12] Mayer, R. E. \& Moreno, R. Nine ways to reduce cognitive load in multimedia learning. Educational Psychologist, 38, (2003). 43-53.

[13] Meek, J. A. Coming Out in the age of the Internet: identity "demarginalization' through virtual group participation. Journal of personal Social Psychology. 75: (2006).681-94.

[14] Moyazzem, H. Impact of Mobile Phone Usage on Academic Performance. An international scientific journal. World Scientific News 118 (2019). 164-180. 